\title{
The Influence of Manufacturing Factors in the Short-Fiber Non-Woven Chestnut Hedgehog Spine- Reinforced Polyester Composite Performance
}

\author{
J. E. Ribeiro, J. Rocha \& L. Queijo
}

To cite this article: J. E. Ribeiro, J. Rocha \& L. Queijo (2019): The Influence of Manufacturing Factors in the Short-Fiber Non-Woven Chestnut Hedgehog Spine-Reinforced Polyester Composite Performance, Journal of Natural Fibers, DOI: 10.1080/15440478.2019.1691109

To link to this article: https://doi.org/10.1080/15440478.2019.1691109

曲 Published online: 19 Nov 2019.

Submit your article to this journal $\widetilde{ }$

LII Article views: 9

Q View related articles $\longleftarrow$

View Crossmark data 


\title{
The Influence of Manufacturing Factors in the Short-Fiber Non-Woven Chestnut Hedgehog Spine-Reinforced Polyester Composite Performance
}

\author{
J. E. Ribeiro ${ }^{a, b}$, J. Rocha ${ }^{a}$, and L. Queijo ${ }^{a}$ \\ aPolytechnic Institute of Bragança, ESTIG, C. Sta. Apolónia, Bragança, Portugal; ${ }^{b} \mathrm{CIMO}$, Mountain Research Centre, \\ C. Sta. Apolónia, Bragança, Portugal
}

\begin{abstract}
One of the most important agricultural products in the northeast of Portugal is sweet chestnuts. In this region only, several tons of this product are produced every year. Sweet chestnuts are enclosed in a hedgehog covered with a large number of short and fine spines and containing more than one nut. This hedgehog, with long spines, does not have any commercial value, and they are considered an agricultural waste that is left in the fields to be incorporated into the soil. In this work, the authors propose to study the influence of some factors in the short-fiber non-woven chestnut hedgehog spine-reinforced polyester composite performance. For this purpose, the tensile properties of chestnut spines were determined by implementing a design of experiments (DOE) approach developed by Taguchi. Thus, the factors that will be controlled are the fiber dispersion which is defined by fiber/matrix mass ratio or weight fraction, the interfacial strength that could be improved using an alkali-silane treatment and, finally, the moisture level in the fibers. For each factor, three levels were used, an $L_{9}$ orthogonal array of experiments was implemented to evaluate tensile and flexural properties. These properties were determined based on results of 54 tests, and the maximum mean values for tensile and flexural strength were $23.5 \mathrm{MPa}$ and $33.6 \mathrm{MPa}$, respectively. The most influential factor for maximizing the tensile strength was the volume fraction of fiber with a contribution of $30 \%$, and most influential factor for maximizing the flexural strength was the moisture level with a contribution of $65 \%$. The determined mean value of tensile strength of the spines was $148 \mathrm{MPa}$.
\end{abstract}

\section{摘要}

葡萄牙东北部最重要的农产品之一是甜栗子。这个地区每年只生产几吨这 种产品. 甜栗子被包围在一只刺猬里, 刺猬身上长满了许多又短又细的 刺, 里面有不止一个坚果. 这种长着长刺的刺猬没有任何商业价值, 它们 被认为是一种农业废弃物, 留在地里, 以便并入土壤. 本文研究了短纤维 无纺栗子刺猬刺增强聚酯复合材料性能的影响因素. 为此, 采用田口的实 验设计方法测定了板栗尖晶石的拉伸性能。因此, 将要控制的因素是由纤 维/基体质量比或重量分数定义的纤维分散性、使用碱-硅烷处理可提高的 界面强度以及纤维中的水分水平.对于每一个因素, 使用三个水平, 实施 $\mathrm{L} 9$ 正交试验阵列来评估拉伸和弯曲性能. 这些性能是根据54个试验的结果确 定的, 拉伸强度和弯曲强度的最大平均值分别为 $23.5 \mathrm{MPa}$ 和 $33.6 \mathrm{MPa}$. 最 大化拉伸强度的最有影响的因素是纤维的体积分数, 贡献率为 $30 \%$, 最大 抗弯强度的影响因素是湿度水平, 贡献率为 $65 \%$ 。测定的尖晶石抗拉强度 平均值为 $148 \mathrm{mpa}$.

\section{KEYWORDS}

Chestnut hedgehog spine; natural fibers; composite; polyester; mechanical properties; manufacturing factors

CONTACT J. E. Ribeiro @ jribeiro@ipb.pt @ Polytechnic Institute of Bragança, ESTIG, C. Sta. Apolónia, Bragança 5301-857, Portugal

Color versions of one or more of the figures in the article can be found online at www.tandfonline.com/wjnf. 


\section{Introduction}

Over the last decade, an increased interest in using natural fibers in situations where synthetic fibers (i.e., glass, carbon or Kevlar fibers) can be substituted has been observed. Natural fiber composites (NFCs) have important advantages because these are considered a renewable resource, for which the production requires less energy. It involves $\mathrm{CO}_{2}$ absorption, whilst returning oxygen to the environment and can be produced at lower cost than synthetic fibers (Lee, Kim, and Yu 2009). However, NFCs have also some limitations, namely, lower durability than the synthetic fiber composites and a greater variability of properties (Lee, Kim, and Yu 2009). Nevertheless, all these characteristics can vary profoundly depending on many factors, such as fiber selection, matrix selection, interfacial strength, fiber dispersion, fiber orientation, composite manufacturing process and porosity (Pickering, Aruan Efendy, and Le 2016).

Natural fibers are, usually, classified based on their origin, which can be mineral, animal or vegetal. Animal fibers consist of proteins (wool or silk) while plant fibers are composed of cellulose (John and Thomas 2008). Nowadays, the natural fibers which have origin in plants are the most used to manufacture NFCs due to its suitability for use in composites with structural requirements. On other hand, plant fiber can be grown in many countries and can be harvested after short periods. Natural fibers are constituted mainly by cellulose, lignin, hemicellulose, pectin, and waxes, and they can be considered, themselves, as natural composites containing mostly cellulose fibrils embedded in lignin matrix. The nature of cellulose and its crystallinity has an important role in the reinforcing efficiency of natural fiber. Cellulose fibrils are aligned along the fiber length, ensuring the maximum tensile and flexural strengths and, additionally, providing rigidity. These mechanical characteristics can be compared with synthetic fibers, commonly with E-glass fibers, and natural fibers like flex, hemp and ramie present the highest specific Young's moduli and tensile strengths, although it should be realized that much variability is found within the literature (Pickering, Aruan Efendy, and Le 2016; Dittenber and Gangarao 2012; La Mantia and Morreale 2011; Bos, Van Den Oever, and Peters 2002). Besides the mechanical properties, the fiber's geographic availability plays a significant role in fiber selection (Abdollah et al. 2015). For this reason, the authors of this work have chosen a natural fiber, chestnut hedgehog spines, which is very common in their region, the northeast of Portugal, and which are, usually, considered an agricultural waste at the end of nut harvest season. Chestnut hedgehog spines usually have lengths between 15 and $30 \mathrm{~mm}$, which leads to considering them as short fibers.

The interfacial adhesion between fiber and matrix plays a fundamental role in the mechanical properties of composites because a good interfacial adhesion is required to achieve a good reinforcement. However, if the interface is to strong and the cracks could propagate, which can reduce the toughness and strength. Nonetheless, for plant-based fiber composites, the interaction between the fibers, which are usually hydrophilic, and the matrices, which are generally hydrophobic, is very limited, leading to a low interfacial adhesion, which affects the mechanical properties. In contrast, low humidity decreases the resistance and the mechanical properties over a long period. To assure a good adhesion, matrix and fibers must be very close and, as is usual in any adhesion phenomenon, the property of wettability is essential to guarantee the adhesion between the adhesive and adherent. In this case, insufficient wetting of the fibers causes interfacial defects, which can act as stress concentrators (Chen et al. 2006) and affect the mechanical properties (Wu and Dzenis 2006). There are different kinds of fiber surface treatments, that can be classified as chemical and physical, and that can improve the fiber wettability and, consequently, improve the interfacial strength (Bénard, Fois, and Grisel 2007; Sinha and Panigrahi 2009; Liu et al. 2008). Interfacial adhesion may take place by different mechanisms, namely mechanical interlocking, chemical bonding, inter-diffusion bonding, and electrostatic bonding (Matthews and Rawlings 1999). In this work, the authors used a chemical surface treatment, which approach includes many different techniques using chemical products like acetyl, benzyl, titanate, peroxide, zirconate, acryl, permanganate, alkali, and silane, among others (Kabir et al. 2012), that can be used singly or in combination (Rong et al. 2001). However, the most commonly used products are alkali, acetyl, and silane (Ismail, Shuhelmy, and Edyham 2002; Mori et al. 2018). Alkaline treatment consists in immersing the fibers in an alkaline solution, usually $\mathrm{NaOH}$, for a period. This treatment removes fiber constituents including lignin, hemicellulose, pectin, and wax, which exposes 
cellulose and increases the surface roughness per unit area, providing an improved interfacial adhesion (Li, Tabil, and Panigrahi 2007). Silane treatment generally involves moistening the fibers in a solution of diluted silane in a water/alcohol mixture that will be broken down into silanol and alcohol in the presence of water. Silanol reacts with the cellulose $\mathrm{OH}$ groups in the natural fibers, forming stable covalent bonds in the cell walls (Agrawal et al. 2000). Silane treatment improves the amount of reticulation in the interface region and increases the fiber surface area, causing a stronger adhesion between the matrix and the fiber (Huda et al. 2008).

A factor that has a great influence over the short-fiber composite properties is the fiber dispersion, particularly for NFCs which normally have hydrophilic fibers and hydrophobic matrices (Mohammed et al. 2015). The fiber dispersion can be influenced by fiber volume fraction (Pan 1993) and by processing parameters like pressure and temperature (Muthuraj et al. 2016). Also, more efficient mixing process implementation, such as using a twin-screw extruder rather than a single-screw extruder, leads to better fiber dispersion. However, this process leads to important fiber damage and, consequently, their substantial length reduction (Beckermann and Pickering 2008). In conclusion, it is possible to say that good fiber dispersion foments good interfacial bonding, reducing voids by guaranteeing that fibers are totally surrounded by the matrix (Peltola et al. 2011). In the present work, the authors analyze the influence of fiber volume fraction which affects, directly, NFC mechanical properties (Arib et al. 2006; Dhakal, Zhang, and Richardson 2007; Brahim and Cheikh 2007).

\section{Fiber characterization}

As far as the authors are aware, chestnut hedgehog spine mechanical characterization is not available, provided by any study. For this reason, tensile tests have been performed to determine the fiber tensile strength and to calculate the material density.

To calculate the chestnut hedgehog spine density, firstly, different spines were cut proximally with the same dimensions and measured by optical measurement process using a microscope (Mitutoyo TM505B). The cut spine samples were dried in an oven for $24 \mathrm{~h}$ at $80^{\circ} \mathrm{C}$ (Zhang et al. 2014), weighed on a precision balance (ADA 210C from Algen Scale), and measured again with the referred microscope. The calculated densities, its mean value (MV) and standard deviation (SD) are presented in Table 1.

To determine the tensile strength of chestnut hedgehog spines, eight spine samples were prepared and individually measured, determining that its mean length and section were of $24.6 \mathrm{~mm}$ and $0.43 \mathrm{~mm}^{2}$, respectively. For the tensile test, the test instrument Instron Electro Plus E1000 with the displacement control device was used, and the test speed was $0.5 \mathrm{~mm} / \mathrm{s}$. In Figure 1, it is possible to observe an example of the outputted stress-strain curve of one tensile test and the sample fixed in position on the test device grips.

The tensile strength value determination was obtained from the eight tensile tests. The results are presented in Table 2 .

Table 1. Calculated densities of hedgehog chestnuts spines.

\begin{tabular}{lc}
\hline Sample & $\begin{array}{c}\text { Density }[\mathrm{g} / \\
\left.\mathrm{cm}^{3}\right]\end{array}$ \\
\hline 1 & 1.650 \\
2 & 1.515 \\
3 & 1.233 \\
4 & 1.277 \\
5 & 1.304 \\
Average & 1.396 \\
Standard Deviation & 0.179 \\
\hline
\end{tabular}




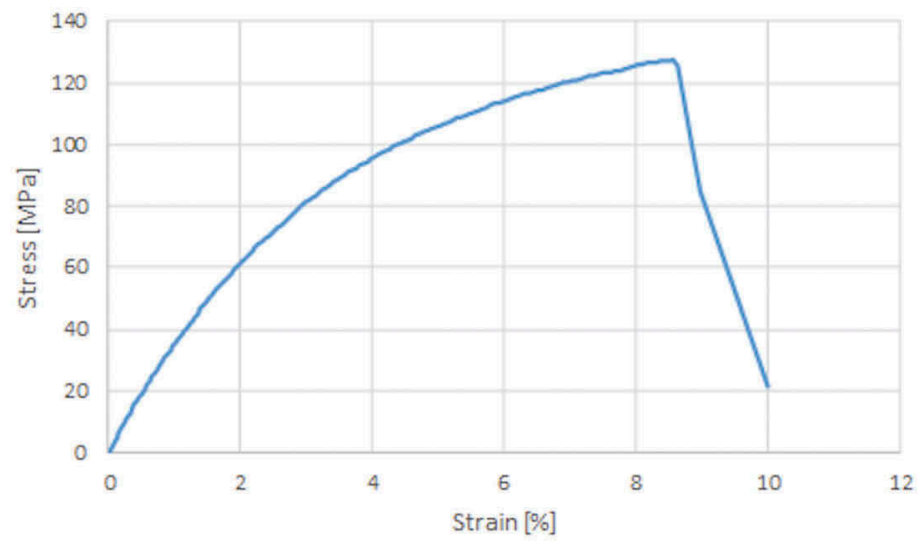

(a)

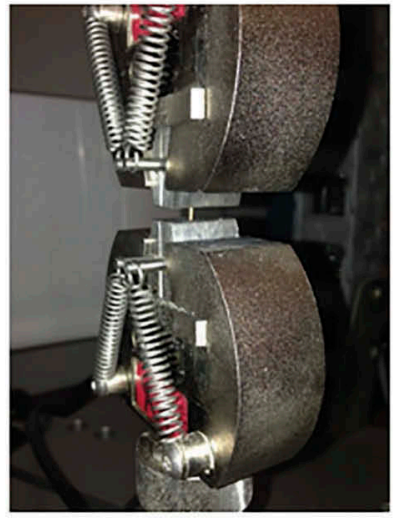

(b)

Figure 1. Stress-strain curve for one of eight tensile tests (a) and the fixation of the spine at the grips (b).

Table 2. Determination of hedgehog chestnuts spines tensile strength.

\begin{tabular}{lc}
\hline Sample & Tensile strength [MPa] \\
\hline 1 & 124.0 \\
2 & 176.2 \\
3 & 103.8 \\
4 & 131.3 \\
5 & 169.9 \\
6 & 157.5 \\
7 & 195.2 \\
8 & 127.9 \\
Average & 148.2 \\
Standard Deviation & 31.2 \\
\hline
\end{tabular}

\section{Experimental procedures}

\section{Experimental design}

To perform a correct experimental design, it is required to identify the significant quality characteristics and to select the predominant control factors. In composite materials, it is possible to control three kinds of factors, which are related with the fiber (Pickering, Aruan Efendy, and Le 2016), the matrix (Luo and Netravali 1999) and the interface between both (George, Sreekala, and Thomas 2001). In this work, the authors have focused on the fiber and on the interface, specifically, on the volume fraction, the fiber moisture and on the fiber surface treatment influence on the adhesion with the matrix. The quality characteristics used to evaluate the changes in the control factors were the tensile strength and the flexural deflection. After defining the control factors and the quality characteristics that will be controlled, it is necessary to define the number of control factor levels (Rocha, Ribeiro, and Queijo 2017). The levels of volume fraction were chosen based on the works developed by Pan (1993) and Messiry (2013), and, using their approach, it is acceptable to process composites within a range of 50-70\% for short fibers with dimensions similar to chestnut hedgehog spines. Humidity level influence on the composite performance has been studied for a long time (Shen and Springer 1977). However, only recently these studies have focused on composites with natural fibers (Bledzki and Gassan 1999). Dhakal, Zhang, and Richardson (2007) analyzed the effect of water absorption on the mechanical properties of hemp fiber-reinforced unsaturated polyester composites, and they verified that hemp fiber could absorb up to $12 \%$ in weight. For this reason, the authors chose a range of less than $2 \%$ until $12 \%$ of water absorption in weight. Finally, for studying 
the adhesion between the fiber and matrix, an alkali-silane treatment with different sodium hydroxide $(\mathrm{NaOH})$ concentrations and a sample of composite without any fiber surface treatment was used. The values of $\mathrm{NaOH}$ concentration were chosen in agreement with Asumani, Reid, and Paskaramoorthy (2012). In their work, they verified that the highest values of mechanical performance occurred for the alkali-silane-treated composites with $5 \%$ of $\mathrm{NaOH}$. The $2 \%$ concentration also used in this study was chosen because it corresponds to an intermediate value. Table 3 summarizes all control factors and their respective levels.

The experimental design for the three control factors using the $\mathrm{L}_{9}$ orthogonal array is presented in Table 4, and that was adapted from Ross (1996).

The $\mathrm{L}_{9}$ orthogonal array presents four columns, one column being left empty to include the error from the experimental tests. One should note that the orthogonality is preserved by including a fourth empty column.

Based on the described experimental design, nine plates were manufactured, each one corresponding to a different combination of control factors and levels. From each plate, three specimens were cut for the tensile test and three for the three-point flexural test.

\section{Materials and composite manufacturing}

The first step to prepare the composite is spine extraction from the chestnut hedgehogs. This is very hard work, and for the present study the extraction was done spine-by-spine using nail pliers. In

Table 3. Control factors of composite.

\begin{tabular}{llccc}
\hline Symbol & Control factors & Level 1 & Level 2 & Level 3 \\
\hline A & $V_{\mathrm{f}}$ : Volume fraction [\%] & 50 & 60 & 70 \\
B & M: Moisture [\% in weight] & $<2$ & $2<\mathrm{M}<8$ & $8<\mathrm{M}<12$ \\
C & ST: Surface Treatment & Untreated & $2 \% \mathrm{NaOH}$ & $5 \% \mathrm{NaOH}$ \\
\hline
\end{tabular}

Table 4. Taguchi $L_{9}$ array.

\begin{tabular}{lcccc}
\hline & A & B & C & D \\
Test number & Volume fraction & Moisture & Surface treatment & error \\
\hline 1 & 1 & 1 & 1 & 1 \\
2 & 1 & 2 & 2 & 2 \\
3 & 1 & 3 & 3 & 3 \\
4 & 2 & 1 & 2 & 3 \\
5 & 2 & 2 & 3 & 1 \\
6 & 2 & 3 & 1 & 2 \\
7 & 3 & 1 & 3 & 2 \\
8 & 3 & 2 & 1 & 3 \\
9 & 3 & 3 & 2 & 1 \\
\hline
\end{tabular}

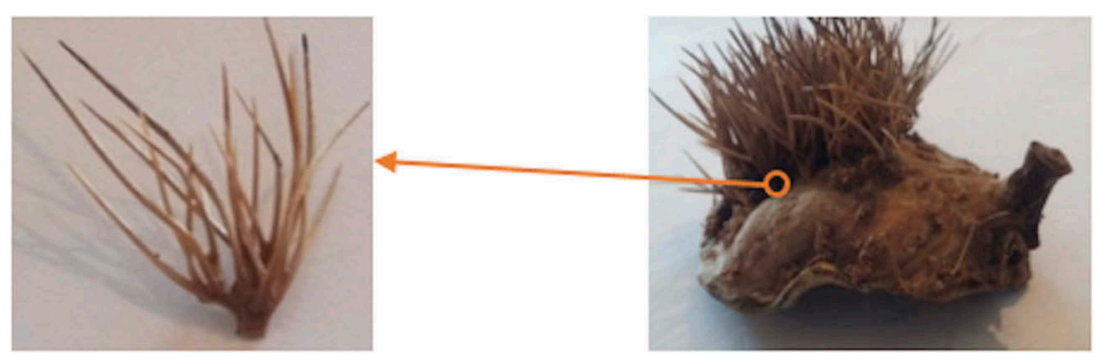

Figure 2. Detail of used chestnut hedgehog spines. 
Figure 2, it is possible to observe details of the chestnut hedgehog spines used for the composites. Naturally, this process to extract the spines is industrially unviable. However, the aim of this study is to characterize the composite, and in future works concerns will be focused on developing more efficient ways of spine extraction.

After the extraction of a quantity of cut spines sufficient to manufacture the nine plates, the second step was to implement the spine surface treatment. This procedure began with the preparation of $\mathrm{NaOH}$ solution at two different concentrations, $2 \%$ and $5 \%$. The spines were immersed in these solutions for $24 \mathrm{~h}$ at $25^{\circ} \mathrm{C}$ temperature, after which they were dried in an oven for $12 \mathrm{~h}$ at a temperature of $45^{\circ} \mathrm{C}$. Subsequently, silane treatment was performed by diluting $5 \%$ in weight of 3-aminopropyltriethoxysilane in a 50\% aqueous solution of methanol, and its $\mathrm{pH}$ was controlled between 4 and 5 by adding acetic acid. The spines were immersed in the solution for 4 $\mathrm{h}$ at a temperature of $28^{\circ} \mathrm{C}$, and, after this period, they were washed with distilled water. Finally, they were dried in the oven at $45^{\circ} \mathrm{C}$ for another $12 \mathrm{~h}$.

The water absorption control was done by weighing spine samples before and after the dehumidification treatment. Before the increase of water quantity in the spines, a dehumidification treatment was implemented, where they were left in the oven at $80^{\circ} \mathrm{C}$ for $24 \mathrm{~h}$. To humidify the spines, they were placed on a grid in a container with water at $45^{\circ} \mathrm{C}$ temperature. The spines were periodically taken off the grid, surface-dried with absorbent paper, and reweighed. The water absorption (WA) was determined using the following equation (Dhakal, Zhang, and Richardson 2007):

$$
W A[\%]=\frac{\left(M_{f}-M_{i}\right)}{M_{i}} \times 100
$$

where $M_{i}$ is the mass of the spine sample before water absorption and $M_{f}$ is the mass of spine sample after the water absorption.

The resin preparation and its mixing with the spines was done immediately after the water absorption control and when the desired humidity was reached. The composite material matrix is based on polyester resin to which was added $1 \%$ of catalyst to activate the polymerization. The quantities of resin and fibers are in agreement with the chosen volume fraction. To obtain these values, the resin and fiber were weighed to guarantee the defined fiber volume fraction $\left(V_{f}\right)$ based on the equation indicated by the ASTM D2584 standard:

$$
V_{f}=\frac{\rho_{m} \times W_{f}}{\rho_{m} \times W_{f}+\rho_{f} \times W_{m}}
$$

where $W_{f}$ is fiber's weight, $W_{m}$ is the matrix material weight, $\rho_{f}$ is the fiber's density and $\rho_{m}$ is the matrix material density.

The spines were mixed with the polyester resin ( $99 \%$ resin with $1 \%$ catalyst) and, while unpolymerized, placed into a two-part mold. This mold was then placed on a press table and subjected to 1 $\mathrm{MPa}$ pressure (Batch, Cumiskey, and Macosko 2002). After $12 \mathrm{~h}$ of polymerization in the press, the composite plate was removed from the mold.

The specimens were cut from the composite plates using a laser system (X252 from GCC), guaranteeing the proper volatile exhaustion. The dimensions and geometry of specimens were

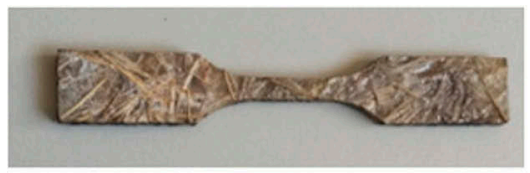

(a)

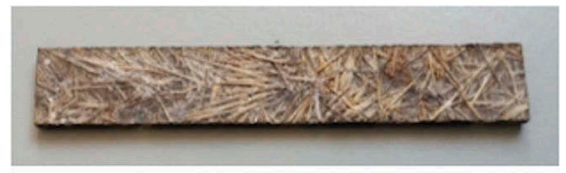

(b)

Figure 3. Specimens used for tensile test (a) and for three-point flexural test (b). 
chosen according to the ASTM D3039M and ASTM D790-03 standards. In Figure 3, it is possible to observe some specimen's examples used for the tensile tests and three-point flexural tests. For each composite plate, corresponding to a combination of the different factors and levels, three specimens for each experimental test were cut, to give a total of 27 for each one.

\section{Mechanical properties}

Both tensile and flexural tests were performed using an Instron ElectroPuls E1000 Test Instrument, equipped with a $50 \mathrm{~kg}$ load cell, after conditioning at $25^{\circ} \mathrm{C}$ according to ASTM standards D3039M and D790-03, respectively. The test speed used for the tensile specimens was $5 \mathrm{~mm} / \mathrm{min}$. For the flexural test (three-point bending), specimens with nominal dimensions of $75 \times 15 \times 4 \mathrm{~mm}^{3}$, a span of $60 \mathrm{~mm}$ and a test speed of $1 \mathrm{~mm} / \mathrm{min}$ were used. Figure 4 shows details of both experimental tests.

For each combination of control factors and levels, the experiment was repeated three times and the tensile strength, and the flexural strength were determined.

The flexural strength was determined using the equation (Hodgkinson 2000):

$$
\sigma=\frac{3 F L}{2 b d^{2}}
$$

where $F$ is the load at the fracture point, $L$ is the length of the support span, $b$ is the width and $d$ is the thickness.

\section{Results and discussion}

The experimental results obtained by the tensile and flexural tests and the resultant tensile and flexural strength are shown in Table 5 .

The experimental results can be converted into a signal-to-noise $(\mathrm{S} / \mathrm{N})$ ratio. Taguchi suggests the use of $\mathrm{S} / \mathrm{N}$ ratio to determine the quality characteristics deviating from the desired values.

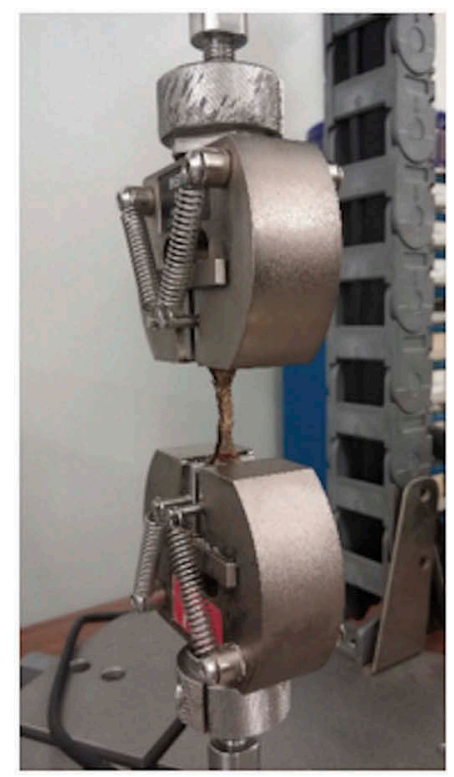

(a)

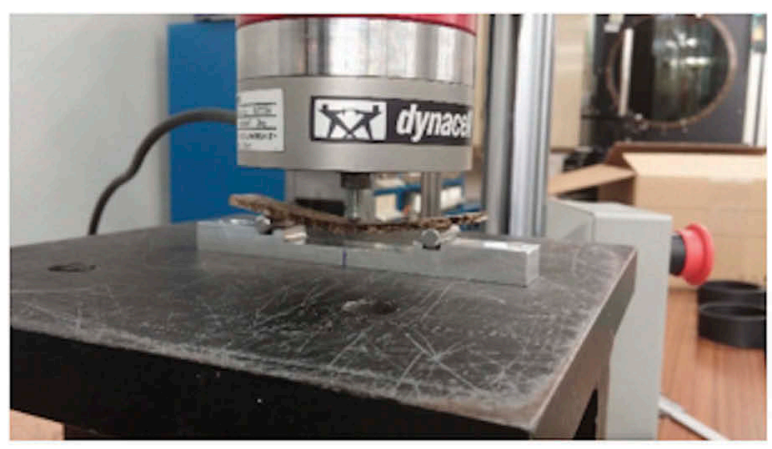

(b)

Figure 4. The tensile test (a) and the three-point flexural test (b). 
Table 5. Experimental results for mechanical properties.

\begin{tabular}{lcc}
\hline Experiment number & Tensile strength [MPa] & Flexural strength [MPa] \\
\hline $1-1$ & 17.9 & 12.08 \\
$1-2$ & 2.9 & 10.50 \\
$1-3$ & 18.0 & 10.24 \\
$2-1$ & 5.1 & 6.08 \\
$2-2$ & 11.2 & 5.93 \\
$2-3$ & 15.5 & 7.09 \\
$3-1$ & 15.5 & 7.16 \\
$3-2$ & 11.1 & 12.79 \\
$3-3$ & 20.0 & 11.06 \\
$4-1$ & 21.4 & 19.50 \\
$4-2$ & 23.1 & 15.23 \\
$4-3$ & 18.5 & 14.59 \\
$5-1$ & 21.3 & 6.79 \\
$5-2$ & 23.2 & 8.10 \\
$5-3$ & 6.5 & 6.75 \\
$6-1$ & 8.2 & 1.70 \\
$6-2$ & 9.7 & 2.46 \\
$6-3$ & 0.7 & 2.86 \\
$7-1$ & 2.7 & 36.56 \\
$7-2$ & 3.3 & 31.73 \\
$7-3$ & 36.3 & 32.44 \\
$8-1$ & 24.6 & 4.61 \\
$8-2$ & 43.3 & 3.40 \\
$8-3$ & 2.7 & 7.46 \\
$9-1$ & 7.9 & 1.64 \\
$9-2$ & 3.1 & 3.03 \\
$9-3$ & 0.3 & 1.76 \\
\hline & &
\end{tabular}

Frequently, there are three categories of quality characteristics in the analysis of the $\mathrm{S} / \mathrm{N}$ ratio, which are the lower-the-better, the higher-the-better, and the nominal-the-better. The $\mathrm{S} / \mathrm{N}$ ratio for each level of control factors is computed based on the $\mathrm{S} / \mathrm{N}$ analysis. Irrespective of the category of the quality characteristics, a greater $\mathrm{S} / \mathrm{N}$ ratio corresponds to better quality characteristics. Then, the optimal level of the control factors is the level with the greatest $\mathrm{S} / \mathrm{N}$ ratio. Moreover, a statistical analysis of variance is accomplished to see which control factors are statistically significant. Using the obtained results of S/N and ANOVA analyses, the optimal combination of the control factors and their levels can be predicted. The goal of the present work is the maximization of tensile and flexural strength, and, for this reason, the category of quality characteristics for $\mathrm{S} / \mathrm{N}$ ratio is thehigher-the-better, which is defined by (Ribeiro, César, and Lopes 2017):

$$
S / N=-10 \log \left(\frac{1}{n} \sum_{i=1}^{n} \frac{1}{y_{i}^{2}}\right)
$$

where $n$ is the number of observations and $y$ is the observed data.

The $\mathrm{S} / \mathrm{N}$ ratios for tensile and flexural strength are represented in Table 6.

Table 6. S/N ratio for tensile and flexural strength.

\begin{tabular}{llllcc}
\hline Test number & $\mathrm{A}$ & $\mathrm{B}$ & $\mathrm{C}$ & $\mathrm{S} / \mathrm{N}_{\mathrm{ts}}$ ratio $[\mathrm{dB}]$ & $\mathrm{S} / \mathrm{N}_{\mathrm{fs}}$ ratio $[\mathrm{dB}]$ \\
\hline 1 & 1 & 1 & 1 & 13.80 & 29.23 \\
2 & 1 & 2 & 2 & 17.73 & 24.51 \\
3 & 1 & 3 & 3 & 23.07 & 28.00 \\
4 & 2 & 1 & 2 & 26.33 & 32.63 \\
5 & 2 & 2 & 3 & 20.34 & 25.59 \\
6 & 2 & 3 & 1 & 1.86 & 15.27 \\
7 & 3 & 1 & 3 & 11.16 & 38.99 \\
8 & 3 & 2 & 1 & 13.33 & 21.48 \\
9 & 3 & 3 & 2 & -5.73 & 14.24 \\
\hline
\end{tabular}


In Table $6, S / N_{t s}$ is the $S / N$ ratio for tensile strength and $S / N_{f s}$ is the $S / N$ ratio for flexural strength.

The signal term in the Taguchi method represents the wanted value (mean) for the output attribute, and noise represents the unwanted square deviation value for the output attribute. Thus, $\mathrm{S} / \mathrm{N}$ ratio is the ratio of the mean to the square deviation. The $\mathrm{S} / \mathrm{N}$ ratio is used by Taguchi to measure the quality attribute or characteristics from the wanted value. For the higher $\mathrm{S} / \mathrm{N}$ ratio, the better category is applied, with the objective of maximizing the tensile and flexural strength. The results of $\mathrm{S} / \mathrm{N}$ for the nine combinations $\mathrm{L}_{9}$ are presented in Table 6 . Their analyses allow discriminating the effect of each control factor for the different levels. The mean $\mathrm{S} / \mathrm{N}$ ratio for each control factor at levels 1,2 and 3 can be computed by averaging the S/N ratios for corresponding experiments. The mean $\mathrm{S} / \mathrm{N}$ ratio for each level of control factor is presented in Tables 7 and 8 , commonly defined as the mean $\mathrm{S} / \mathrm{N}$ ratio response for the tensile and flexural strength. The total mean $\mathrm{S} / \mathrm{N}$ ratio is $13.54 \mathrm{~dB}$ for tensile strength and $25.55 \mathrm{~dB}$ for flexural strength.

Figures 5 and 6 show the $\mathrm{S} / \mathrm{N}$ ratio response graph for tensile and flexural strength, respectively. One gets a high $\mathrm{S} / \mathrm{N}$ ratio for smaller variance of tensile and flexural strength around the desired value. Nevertheless, the relative importance of the control factors for the tensile and flexural strength

Table 7. Response table mean $\mathrm{S} / \mathrm{N}$ ratio for tensile strength and significant interaction.

\begin{tabular}{llccrc}
\hline & & \multicolumn{4}{c}{ Mean S/N ratio [dB] } \\
\cline { 3 - 6 } Symbol & \multicolumn{1}{c}{ Control factor } & Level 1 & Level 2 & Level 3 & Max-min \\
\hline A & V: Volume fraction [\%] & 18.20 & 16.18 & 6.25 & 11.95 \\
B & M: Moisture [\% in weight] & 17.10 & 17.13 & 6.40 & 10.73 \\
C & ST: Surface Treatment & 9.66 & 12.78 & 18.91 & 8.53 \\
\hline
\end{tabular}

Table 8. Response table mean $\mathrm{S} / \mathrm{N}$ ratio for flexural strength and significant interaction.

\begin{tabular}{llcccr}
\hline & & \multicolumn{4}{c}{ Mean S/N ratio [dB] } \\
\cline { 3 - 6 } Symbol & Control factor & Level 1 & Level 2 & Level 3 & Max-min \\
\hline A & V $:$ Volume fraction [\%] & 27.25 & 24.50 & 24.91 & 2.75 \\
B & M: Moisture [\% in weight] & 33.62 & 23.86 & 19.17 & 14.44 \\
C & ST: Surface Treatment & 21.99 & 23.79 & 30.86 & 8.87 \\
\hline
\end{tabular}

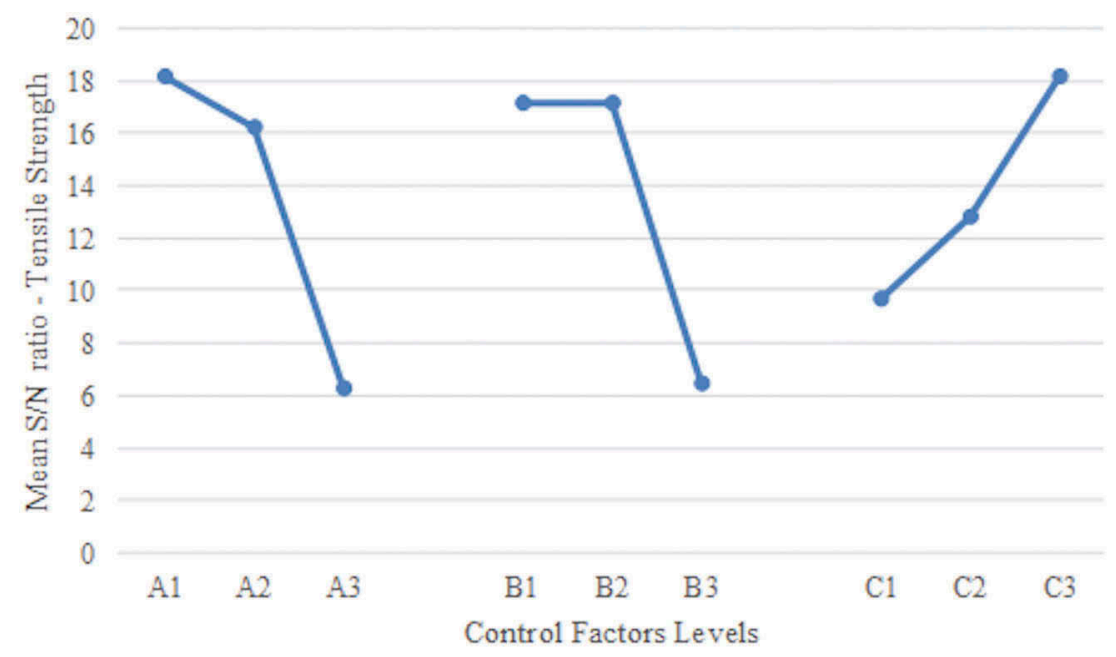

Figure 5. Mean $\mathrm{S} / \mathrm{N}$ ratio graph for tensile strength. 


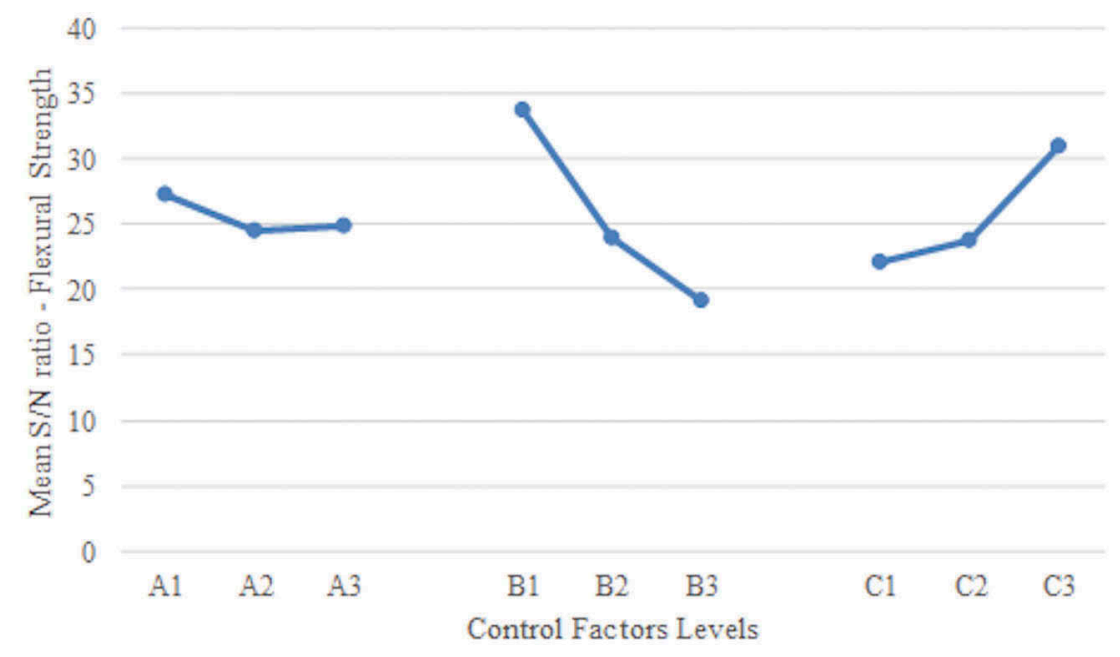

Figure 6. Mean S/N ratio graph for flexural strength.

still need to be identified more accurately using an ANOVA analysis in order to determine the optimal combinations of the control factors levels. It can, also, be verified, from Figures 5 and 6 analysis, that the moisture value influences the tensile and flexural strength values. The lower moisture values correspond to the higher $\mathrm{S} / \mathrm{N}$ ration which means that produces the lower variance in the evaluated mechanical characteristics. Thus, it is advisable to maintain the moisture values under control and with as lowest as possible value.

The goal of the analysis of variance is to determine which design of control factors meaningfully affect the tensile and flexural strength. This goal is achieved by splitting the variability of the $\mathrm{S} / \mathrm{N}$ ratios, that is measured by the sum of the squared deviations from the total mean $\mathrm{S} / \mathrm{N}$ ratio, in the contributions of each control factor and the error. The results of variance of each control factor are shown in Tables 9 and 10, where DF is degree of freedom, SS is sum of squares and MS are the mean squares.

The F-test is a statistic tool to verify which design parameters significantly affect the quality characteristics. This is defined as the ratio of the mean squared deviations to the mean squared error.

The analysis of the F-test values reveals that, for tensile strength, the volume fraction and the level of moisture are the most significant control factors, with almost $30 \%$ for volume fraction, followed by the moisture and then the surface treatment, respectively, with $28 \%$ and $13 \%$ contribution. The

Table 9. ANOVA for tensile strength.

\begin{tabular}{lccccc}
\hline Source & DF & SS & MS & F-ratio & Contribution [\%] \\
\hline A: VF & 2 & 245.4 & 122.71 & 1.00 & $29.50 \%$ \\
B: M & 2 & 229.6 & 114.80 & 0.94 & $27.60 \%$ \\
C: ST & 2 & 111.8 & 55.88 & 0.46 & $13.44 \%$ \\
Error & 2 & 245.3 & 122.63 & & $29.48 \%$ \\
Total & 8 & 832 & & & $100 \%$ \\
\hline
\end{tabular}

Table 10. ANOVA for flexural strength.

\begin{tabular}{lccccc}
\hline Source & DF & SS & MS & F-ratio & Contribution [\%] \\
\hline A: VF & 2 & 13.23 & 6.616 & 0.43 & $2.64 \%$ \\
B: M & 2 & 325.79 & 152.894 & 10.63 & $64.97 \%$ \\
C: ST & 2 & 131.79 & 65.895 & 4.3 & $26.28 \%$ \\
Error & 2 & 30.66 & 15.328 & & $6.11 \%$ \\
Total & 8 & 501.46 & & & $100 \%$ \\
\hline
\end{tabular}


optimal control factors for tensile strength are the volume fraction at level 1, the moisture at level 2 and, finally, the surface treatment at level 3. On the other hand, for flexural strength the most significant control factors are the moisture and the surface treatment. In this case, the moisture has a contribution of $65 \%$, the surface treatment contributes with $26 \%$ and the volume fraction with only $3 \%$. The control factors which maximize the flexural strength are the moisture level at level 1, the surface treatment at level 3 and volume fraction at level 1 .

\section{Conclusions}

The chestnut hedgehog spine mean tensile strength is around $150 \mathrm{MPa}$, however the standard deviation is greater than $30 \mathrm{MPa}$. These values of mechanical properties allow the use of these natural fibers for structural components which have low loads.

The three control factors of NFCs analyzed were the volume fraction, the fiber's level of humidity and the surface treatment. The goal of this work was to maximize the values of tensile and flexural strength, and for that reason the authors implemented an array of experiments based on the Taguchi $\mathrm{L}_{9}$ array.

The maximum value of mean tensile strength was $23.5 \mathrm{MPa}$ for a combination of $70 \%$ of volume fraction, a moisture level in fiber between $2 \%$ and $8 \%$ and without any fiber surface treatment. On the other hand, the higher mean value for flexural strength was $33.6 \mathrm{MPa}$, which happened using a combination of $70 \%$ of volume fraction (eighth test of Table 4), less than $2 \%$ moisture and a fiber surface treatment with $5 \%$ of $\mathrm{NaOH}$ concentration (seventh test of Table 4). However, for S/N evaluation the results are very different, and the maximum value occurred for test 4 with $26.33 \mathrm{~dB}$. This difference is related to the measured values, because despite the mean value of test 8 being higher than the test 4 , the variance of this last one is smaller.

From the ANOVA analysis, it is possible to identify the most influential factor for tensile strength, which is the fiber volume fraction with a contribution of $30 \%$. However, for flexural strength, the factor that has a stronger contribution is the moisture level with a contribution of $65 \%$.

\section{References}

Abdollah, M. F. B., F. F. Shuhimi, N. Ismail, H. Amiruddin, and N. Umehara. 2015. Selection and verification of Kenaf fibres as an alternative friction material using weighted decision matrix method. Materials and Design 67:577-82. doi:10.1016/j.matdes.2014.10.091.

Agrawal, R., N. S. Saxena, K. B. Sharma, S. Thomas, and M. S. Sreekala. 2000. Activation energy and crystallization kinetics of untreated and treated oil palm fibre reinforced phenol formaldehyde composites. Materials Science and Engineering: A 277 (1-2):77-82. doi:10.1016/S0921-5093(99)00556-0.

Arib, R. M. N., S. M. Sapuan, M. M. H. M. Ahmad, M. T. Paridah, and H. M. D. Khairul Zaman. 2006. Mechanical properties of pineapple leaf fibre reinforced polypropylene composites. Materials and Design 27 (5):391-96. doi:10.1016/j.matdes.2004.11.009.

Asumani, O. M. L., R. G. Reid, and R. Paskaramoorthy. 2012. The effects of alkali-silane treatment on the tensile and flexural properties of short fibre non-woven Kenaf reinforced polypropylene composites. Composites Part A: Applied Science and Manufacturing 43 (9):1431-40. Elsevier Ltd. doi:10.1016/j.compositesa.2012.04.007.

Batch, G. L., S. Cumiskey, and C. W. Macosko. 2002. Compaction of fiber reinforcements. Polymer Composites 23 (3):307-18. doi:10.1002/pc.10433.

Beckermann, G. W., and K. L. Pickering. 2008. Engineering and evaluation of hemp fibre reinforced polypropylene composites: Fibre treatment and matrix modification. Composites Part A: Applied Science and Manufacturing 39 (6):979-88. doi:10.1016/j.compositesa.2008.03.010.

Bénard, Q., M. Fois, and M. Grisel. 2007. Roughness and fibre reinforcement effect onto wettability of composite surfaces. Applied Surface Science 253 (10):4753-58. doi:10.1016/j.apsusc.2006.10.049.

Bledzki, A. K., and J. Gassan. 1999. Composites reinforced with cellulose based fibres. Progress in Polymer Science (Oxford) 24 (2):221-74. doi:10.1016/S0079-6700(98)00018-5.

Bos, H. L., M. J. A. Van Den Oever, and O. Peters. 2002. Tensile and compressive properties of flax fibres for natural fibre reinforced composites. Journal of Materials Science 7:1683-92. doi:10.1023/A:1014925621252.

Brahim, S. B., and R. B. Cheikh. 2007. Influence of fibre orientation and volume fraction on the tensile properties of unidirectional Alfa-polyester composite. Composites Science and Technology 67 (1):140-47. doi:10.1016/j. compscitech.2005.10.006. 
Chen, P., C. Lu, Q. Yu, Y. Gao, J. Li, and X. Li. 2006. Influence of fiber wettability on the interfacial adhesion of continuous fiber-reinforced PPESK composite. Journal of Applied Polymer Science 102 (3):2544-51. doi:10.1002/ app. 24681 .

Dhakal, H. N., Z. Y. Zhang, and M. O. W. Richardson. 2007. Effect of water absorption on the mechanical properties of hemp fibre reinforced unsaturated polyester composites. Composites Science and Technology 67 (7-8):1674-83. doi:10.1016/j.compscitech.2006.06.019.

Dittenber, D. B., and H. V. S. Gangarao. 2012. Critical review of recent publications on use of natural composites in infrastructure. Composites Part A: Applied Science and Manufacturing 43 (8):1419-29. Elsevier Ltd. doi:10.1016/j. compositesa.2011.11.019.

George, J., M. S. Sreekala, and S. Thomas. 2001. A review on interface modification and characterization of natural fiber reinforced plastic composites. Polymer Engineering \& Science 41 (9):1471-85. doi:10.1002/ pen.10846.

Hodgkinson, J. M. 2000. Mechanical testing of advanced fibre composites. Cambridge: Woodhead Publishing.

Huda, M. S., L. T. Drzal, A. K. Mohanty, and M. Misra. 2008. Effect of fiber surface-treatments on the properties of laminated biocomposites from poly(Lactic Acid) (PLA) and Kenaf fibers. Composites Science and Technology 68 (2):424-32. doi:10.1016/j.compscitech.2007.06.022.

Ismail, H., S. Shuhelmy, and M. R. Edyham. 2002. The effects of a silane coupling agent on curing characteristics and mechanical properties Og bamboo fibre filled natural rubber composites. European Polymer Journal 38 (1):39-47. doi:10.1016/S0014-3057(01)00113-6.

John, M. J., and S. Thomas. 2008. Biofibres and biocomposites. Carbohydrate Polymers 71 (3):343-64. doi:10.1016/j. carbpol.2007.05.040.

Kabir, M. M., H. Wang, K. T. Lau, and F. Cardona. 2012. Chemical treatments on plant-based natural fibre reinforced polymer composites: An overview. Composites Part B: Engineering 43 (7):2883-92. Elsevier Ltd. doi:10.1016/j. compositesb.2012.04.053.

La Mantia, F. P., and M. Morreale. 2011. Green composites: A brief review. Composites Part A: Applied Science and Manufacturing 42 (6):579-88. Elsevier Ltd. doi:10.1016/j.compositesa.2011.01.017.

Lee, B. H., H. J. Kim, and W. R. Yu. 2009. Fabrication of long and discontinuous natural fiber reinforced polypropylene biocomposites and their mechanical properties. Fibers and Polymers 10 (1):83-90. doi:10.1007/s12221009-0083-z.

Li, X., L. G. Tabil, and S. Panigrahi. 2007. Chemical treatments of natural fiber for use in natural fiber-reinforced composites: A review. Journal of Polymers and the Environment 15 (1):25-33. doi:10.1007/s10924-006-0042-3.

Liu, Z., C. Sun, Z.-W. Liu, and J. Lu. 2008. Adjustable wettability of methyl methacrylate modified ramie fiber. Journal of Applied Polymer Science 109 (5):2888-94. doi:10.1002/(ISSN)1097-4628.

Luo, S., and A. N. Netravali. 1999. Mechanical and thermal properties of environment-friendly 'green' composites made from pineapple leaf fibers and poly (Hydroxybutyrate-co-valerate) Resin. Polymer Composites 4:3709-19. doi:10.1002/pc.10363/abstract.

Matthews, F. L., and R. D. Rawlings. 1999. Composite materials: Engineering and science. New York: Published by Woodhead Publishing Limited.

Messiry, M. E. 2013. Theoretical analysis of natural fiber volume fraction of reinforced composites. Alexandria Engineering Journal 52 (3):301-06. Faculty of Engineering, Alexandria University. doi:10.1016/j.aej.2013.01.006.

Mohammed, L., M. N. M. Ansari, G. Pua, M. Jawaid, and M. Saiful Islam. 2015. A review on natural fiber reinforced polymer composite and its applications. International Journal of Polymer Science 2015:1-15. doi:10.1155/2015/ 243947.

Mori, S., C. Tenazoa, S. Candiotti, E. Flores, and S. Charca. 2018. Assessment of Ichu fibers extraction and their use as reinforcement in composite materials. Journal of Natural Fibers. 1-16. Taylor \& Francis. doi:10.1080/ 15440478.2018.1527271.

Muthuraj, R., M. Misra, F. Defersha, and A. K. Mohanty. 2016. Influence of processing parameters on the impact strength of biocomposites: A statistical approach. Composites Part A: Applied Science and Manufacturing 83:120-29. Elsevier Ltd. doi:10.1016/j.compositesa.2015.09.003.

Pan, N. 1993. Theoretical determination of the optimal fiber volume fraction and fiber-matrix property compatibility of short fiber composites. Polymer Composites 14 (2):85-93. doi:10.1002/(ISSN)1548-0569.

Peltola, H., B. Madsen, R. Joffe, and K. Nättinen. 2011. The influence of biocomposite processing and composition on natural fiber length, dispersion and orientation. Journal of Materials Science and Engineering A 1:190-98.

Pickering, K. L., M. G. Aruan Efendy, and T. M. Le. 2016. A review of recent developments in natural fibre composites and their mechanical performance. Composites Part A: Applied Science and Manufacturing 83:98-112. doi:10.1016/j. compositesa.2015.08.038.

Ribeiro, J., M. B. César, and H. Lopes. 2017. Optimization of machining parameters to improve the surface quality. Procedia Structural Integrity 5:355-62. doi:10.1016/j.prostr.2017.07.182. 
Rocha, J., J. E. Ribeiro, and L. Queijo. 2017. Comparison of mechanical properties of polyester composites reinforced with autochthonous natural fibres: Flax and hemp. In Materials design and applications, ed. L. Silva, 125-34. Cham: Springer. doi:10.1007/978-3-319-50784-2_10.

Rong, M. Z., M. Q. Zhang, Y. Liu, G. C. Yang, and H. M. Zeng. 2001. The effect of fiber treatment on the mechanical properties of unidirectional sisal-reinforced epoxy composites. Composites Science and Technology 61 (10):1437-47. doi:10.1016/S0266-3538(01)00046-X.

Ross, P. J. 1996. Taguchi techniques for quality engineering, Edited by McGraw-Hill, 2nd Editio, New York: McGrawHill. https://www.amazon.com/Taguchi-Techniques-Quality-Engineering-Phillip/dp/0070539588.

Shen, C.-H., and G. S. Springer. 1977. Effects of moisture and temperature on the tensile strength of composite materials. Journal of Composite Materials 11 (1):2-16. doi:10.1177/002199837701100102.

Sinha, E., and S. Panigrahi. 2009. Effect of plasma treatment on structure, wettability of jute fiber and flexural strength of its composite. Journal of Composite Materials 43 (17):1791-802. doi:10.1177/0021998309338078.

Wu, X. F., and Y. A. Dzenis. 2006. Droplet on a fiber: Geometrical shape and contact angle. Acta Mechanica 185 (3-4):215-25. doi:10.1007/s00707-006-0349-0.

Zhang, D., N. R. Milanovic, Y. Zhang, F. Su, and M. Miao. 2014. Effects of humidity conditions at fabrication on the interfacial shear strength of flax/unsaturated polyester composites. Composites Part B: Engineering 60:186-92. Elsevier Ltd. doi:10.1016/j.compositesb.2013.12.031. 